\title{
Potential Mediator of Inflammation
}

\author{
PHAGOCYTE-DERIVED OXIDANTS SUPPRESS THE ELASTASE-INHIBITORY
} CAPACITY OF ALPHA ${ }_{1}$-PROTEINASE INHIBITOR IN VITRO

\author{
HaRvey CarP and Aaron JanOFf, Department of Pathology, Health Sciences Center, \\ State University of New York at Stony Brook, Stony Brook, New York 11794
}

\begin{abstract}
A B S T RACT Human polymorphonuclear leukocytes, monocytes, or pulmonary alveolar macrophages, stimulated in vitro by phorbol myristate acetate (PMA), released reactive oxygen species able to suppress the elastase inhibitory capacity (EIC) of human serum. Immunoelectrophoresis using antibodies against $\alpha_{1^{-}}$ proteinase inhibitor $\left(\alpha_{1}-\mathrm{Pi}\right)$ and elastase showed that inactivation of $\alpha_{1}-\mathrm{Pi}$ was responsible for the decreased serum EIC. Treatment of phagocyte-inactivated serum with a reducing agent (dithiothreitol) resulted in significant recovery of EIC, suggesting that $\alpha_{1}-\mathrm{Pi}$ had been oxidatively inactivated. Serum EIC was partially protected by superoxide dismutase or catalase. Hydrogen peroxide alone had no effect on serum EIC. Thus, neither $\mathrm{H}_{2} \mathrm{O}_{2}$ nor $\mathrm{O}_{2}^{-}$alone, but a product of the two, may have oxidatively inactivated $\alpha_{1}-\mathrm{Pi}$. In support of the foregoing, neutrophils or monocytes from a patient
\end{abstract} with chronic granulomatous disease failed to produce detectable levels of $\mathrm{O}_{2}^{-}$after incubation with PMA. These cells also failed to suppress serum EIC. In the case of PMA-stimulated polymorphonuclear leukocytes or monocytes, extracellular myeloperoxidase may have also played a role in $\alpha_{1}$ - $\mathrm{Pi}$ inactivation since serum EIC was partly protected by azide, cyanide, or the depletion of extracellular chloride. Indeed, in a cell-free system consisting of purified myeloperoxidase, a glucose oxidase $-\mathrm{H}_{2} \mathrm{O}_{2}$-generating system, and $\mathrm{Cl}^{-}$, the EIC of human serum or purified $\alpha_{1}-\mathrm{Pi}$ could also be suppressed. Omission of any single reactant prevented this effect, as did $\mathrm{NaN}_{3}$ or catalase, suggesting that enzymatically active myeloperoxidase and $\mathrm{H}_{2} \mathrm{O}_{2}$ were necessary. Immunoelectrophoresis of myeloperoxidase-inactivated serum showed that, as before, inactivation of $\alpha_{1}-\mathrm{Pi}$ was responsible for the decreased EIC. Treating myeloperoxidase-inactivated serum with dithiothreitol led to significant recovery of

\footnotetext{
Address reprint requests to Dr. Aaron Janoff.

Received for publication 25 January 1980 and in revised form 16 June 1980.
}

EIC, again suggesting that oxidative inactivation of $\alpha_{1}-\mathrm{Pi}$ had occurred. Oxidative inactivation of $\alpha_{1}-\mathrm{Pi}$ in the microenvironment of inflammatory cells, at sites of acute or chronic inflammation, may allow proteases released from these cells to damage adjacent connective tissue components more readily.

\section{INTRODUCTION}

Human leukocytes contain potentially harmful substances within their cytoplasmic granules, including proteases capable of degrading connective tissue structures (1). These proteases include human polymorphonuclear leukocyte $(\mathrm{PMN})^{1}$ elastase (2) and cathepsin-G (3). PMN accumulate at sites of inflammation and these enzymes may escape to the outside of the cell with subsequent damage to surrounding connective tissue structures (4). In addition, mononuclear phagocytes are able to secrete an elastase (5). There is, however, a system of antiproteases in the circulation and tissue fluids that inactivates proteases released from PMN (6). $\alpha_{1-}$ proteinase inhibitor $\left(\alpha_{1}-\mathrm{Pi}\right)$ is an important component of the antiprotease system in man and is responsible for $>90 \%$ of the elastase inhibitory capacity (EIC) of normal human serum (6). The local balance between released protease and tissue antiprotease is considered important in determining whether inflammation will damage connective tissue (6).

Recent reports have shown that oxidation inactivates $\alpha_{1}-\mathrm{Pi}(7-10)$. This is attributed to oxidation of methionine residues in or near the active site of $\alpha_{1}-\mathrm{Pi}(7-10)$. Because leukocytes produce and release several reac-

\footnotetext{
${ }^{1}$ Abbreviations used in this paper: $\alpha_{1}-\mathrm{Pi}, \alpha_{1}$-proteinase inhibitor; CAT, catalase; CGD, chronic granulomatous disease; DTT, dithiothreitol; EIC, elastase inhibitory capacity; HBSSG, glucose in Hank's balanced salt solution; HICAT, heat-inactivated CAT; IEP, immunoelectrophoresis; MPO, myeloperoxidase; MNC, monocyte; PAM, pulmonary alveolar macrophage; PMA, phorbol myristate acetate; PMN, polymorphonuclear leukocyte; SOD, superoxide dismutase.
} 
tive oxygen species during phagocytosis (11), the local balance between protease and antiprotease may be further disrupted during inflammation by the oxidative inactivation of $\alpha_{1}-\mathrm{Pi}$ in the microenvironment of these cells. In this event, tissue components adjacent to leukocytes at sites of inflammation would be even more susceptible to damage by proteases simultaneously released from the phagocytes.

In support of this hypothesis, we recently reported (12) that human PMN, stimulated by opsonized antigen-antibody complexes bound to the outer surface of a dialysis membrane, produce oxidants able to inactivate $\alpha_{1}-\mathrm{Pi}$ inside the dialysis bag. We also presented indirect evidence showing that inactivation of $\alpha_{1}-\mathrm{Pi}$ in this system was dependent on hydrogen peroxide $\left(\mathrm{H}_{2} \mathrm{O}_{2}\right)$, superoxide $\left(\mathrm{O}_{2}^{-}\right)$, and myeloperoxidase (MPO). In the same study, a cell-free superoxide-generating system was shown to inactivate $\alpha_{1}-\mathrm{Pi}$ (12). A closely related study (13) demonstrated that purified MPO can inactivate $\alpha_{1}-\mathrm{Pi}$ in the presence of $\mathrm{H}_{2} \mathrm{O}_{2}$ and halide ions at acid $\mathrm{pH}$.

We have extended our studies of these reactions to include nonphagocytic stimuli, such as membraneperturbing agents, and cells of chronic as well as acute inflammation. The present report demonstrates that human PMN, monocytes (MNC) and pulmonary alveolar macrophages (PAM) stimulated in vitro by phorbol myristate acetate (PMA) are capable of oxidatively inactivating $\alpha_{1}-\mathrm{Pi}$. Our evidence shows that inactivation of $\alpha_{1}$-Pi depends, at least in part, on $\mathrm{O}_{2}^{-}, \mathrm{H}_{2} \mathrm{O}_{2}$, and MPO. MNC and PMN from a patient with chronic granulomatous disease, in which generation of $\mathrm{O}_{2}^{-}$and $\mathrm{H}_{2} \mathrm{O}_{2}$ is depressed, failed to inactivate $\alpha_{1}-\mathrm{Pi}$ when exposed to PMA. Finally, purified MPO, in a cell-free system, inactivated $\alpha_{1}-\mathrm{Pi}$ at physiological $\mathrm{pH}$ in a reaction dependent on $\mathrm{H}_{2} \mathrm{O}_{2}$ and $\mathrm{Cl}^{-}$.

\section{METHODS}

Preparation of leukocytes. PMN and MNC were prepared from the peripheral blood of healthy volunteers and from a patient with chronic granulomatous disease by a modification of the technique of Böyum (14). Cells were suspended briefly in Hank's balanced salt solution ( $\mathrm{pH} 7.8$ ) containing $0.2 \%$ glucose (HBSSG) in place of diluted plasma, and centrifuged at $160 \mathrm{~g}$ for $20 \mathrm{~min}$ in the cold to separate the leukocytes from the bulk of platelets, before Ficoll-Hypaque separation. Typical PMN preparations contained 97-99\% PMN and $<3 \%$ mononuclear cells, as determined by differential counting in a hemocytometer. Cells were suspended in HBSSG ( $\mathrm{pH} \mathrm{7.8)}$ containing $4 \%$ (vol/vol) human serum or other reactants to give a final concentration of $1.6 \times 10^{6} \mathrm{PMN} / \mathrm{ml}$. Over $95 \%$ of the PMN excluded trypan blue before and after the experimental period.

The mononuclear cells were removed from the HBSS/ Ficoll-Hypaque interface and washed three times with 15 vol of HBSSG (pH 7.8). The percent MNC in washed preparations was estimated by differential counting in a hemocytometer and $1.5 \times 10^{6} \mathrm{MNC}$ suspended in HBSSG were poured into a 35-mm diameter tissue-culture dish. After incubation for $\mathbf{2 . 5}$ h at $37^{\circ} \mathrm{C}$, the culture dishes were washed with HBSSG to remove nonadherent cells. Typical adherent MNC preparations contained $>94 \% \mathrm{MNC}$ and $<1.4 \%$ granulocytes (the remainder being lymphocytes). Sufficient HBSSG containing $4 \%$ (vol/vol) human serum was added to each culture dish to give a final concentration of $1.6 \times 10^{6}$ adherent $\mathrm{MNC} / \mathrm{ml}$. Over $94 \%$ of the MNC excluded trypan blue before and after the experimental period.

Bronchoscopic, subsegmental, sterile-saline lavage was performed by standard procedure on two male, noninfected, former smokers undergoing diagnostic fiberoptic bronchoscopy. Only cells from normal lobes were used. Recovered cells were separated from lavage fluid by centrifugation at $200 \mathrm{~g}$ for $15 \mathrm{~min}$ and washed three times with HBSSG (pH 7.8). The percent macrophages in washed preparations was estimated by differential counting in a hemocytometer, and $6 \times 10^{4}$ macrophages suspended in HBSSG were poured into a $6 \mathrm{~mm}$ diameter tissue-culture dish. After incubation for $2.5 \mathrm{~h}$ at $37^{\circ} \mathrm{C}$, the culture dishes were rinsed vigorously with HBSSG to remove nonadherent cells. Typical adherent macrophage preparations contained $>95 \%$ macrophages and $<1 \%$ PMN (the remainder being lymphocytes). Sufficient HBSSG containing $4 \%$ ( $\mathrm{vol} / \mathrm{vol}$ ) human serum was added to each culture dish to give a final concentration of $1.6 \times 10^{6}$ adherent PAM $/ \mathrm{ml}$. Over $92 \%$ of the PAM excluded trypan blue before and after the experimental period.

Source of elastase inhibitor. Dilutions of a standard human serum containing $2.2 \mathrm{mg} / \mathrm{ml}$ of $\alpha_{1}-\mathrm{Pi}$ (determined by radial immunodiffusion) or purified $\alpha_{1}-\mathrm{Pi}$ (a gift of Dr. J. Travis, University of Georgia) were used as sources of elastase inhibitor.

Assay of EIC. Each reaction was run in triplicate. $50 \mu \mathrm{l}$ of a solution to be tested for EIC was mixed with $20 \mu$ l of 0.3 $\mu \mathrm{g} / \mu \mathrm{l}$ porcine pancreatic elastase (Elastin Products Co., St. Louis, Mo.). After incubation for $5 \mathrm{~min}$ at $37^{\circ} \mathrm{C}$, the elastase activity was measured using succinyl-L-alanyl-L-alanyl-Lalanyl-p-nitroanilide (Sigma Chemical Co., St. Louis, Mo.) as substrate (15).

Immunoelectrophoresis. $50 \mu \mathrm{l}$ of a solution to be analyzed by immunoelectrophoresis (IEP) was incubated with $5 \mu$ l of $0.6 \mu \mathrm{g} / \mu \mathrm{l}$ porcine pancreatic elastase (molar ratio of active elastase: $\alpha_{1}-\mathrm{Pi}=1$ ) for $5 \mathrm{~min}$ at $37^{\circ} \mathrm{C} .10 \mu$ l of the reaction mixture was analyzed by IEP as previously described (8) using antiserum against human $\alpha_{1}-\mathrm{Pi}$ (Accurate Chemical \& Scientific Corp., Hicksville, N. Y.) and antiserum against porcine pancreatic elastase (prepared by us).

Special reagents and assays. Leukocyte $\mathrm{O}_{2}^{-}$production was measured by a modification of the method of McCord and Fridovich (16). Each reaction was run in triplicate. Leukocytes were incubated with $80 \mu \mathrm{M}$ cytochrome $c$, after which the samples were centrifuged at $200 \mathrm{~g}$ for $15 \mathrm{~min}$ in the cold to remove all cells. The absorbance of the supernate at $550 \mathrm{~nm}$ was measured. Some reaction mixtures contained superoxide dismutase (SOD) $(400 \mathrm{U} / \mathrm{ml})$. Controls containing all reagents except leukocytes were incubated in parallel and used as blanks.

PMA (a gift of Dr. W. Troll, New York University School of Medicine) was stored at $-80^{\circ} \mathrm{C}$ as a stock solution $(1 \mathrm{mg} / \mathrm{ml})$ in methyl alcohol. SOD (Type 1, Sigma Chemical Co., St. Louis, Mo.) was also assayed according to McCord and Fridovich (16). Both native and heat-inactivated SOD were diluted in $2 \mathrm{mM} \mathrm{Na} \mathrm{ND}_{2}$ EDA and then dialyzed against buffer before use to remove free metals. Catalase (CAT) (C-40, Sigma Chemical Co., St. Louis, Mo.) was freed from contaminating SOD by repeated washings through an XM100A diaflo ultrafiltration membrane (Amicon Corp., Lexington, Mass.). Our preparations of SOD and CAT were found to be free of crosscontamination. Glucose oxidase (Type V) was obtained from Sigma Chemical Co. (St. Louis, Mo.). Purified canine MPO 
was a gift of Dr. J. Schultz (Papanicolaou Cancer Research Institute). Peroxidase activity was determined by monitoring the peroxidase-catalyzed oxidation of $o$-dianisidine (Sigma Chemical Co., St. Louis, Mo.) (17). $\beta$-glucuronidase activity was measured by the method of Bretz and Baggiolini (17). Heat-inactivated MPO, CAT, and SOD were autoclaved for 20 $\mathrm{min}$ at $120^{\circ} \mathrm{C}$ and then centrifuged at $10,000 \mathrm{~g}$ for $15 \mathrm{~min}$.

\section{RESULTS}

Inactivation of elastase inhibitor by PMA-stimulated phagocytes. To study the effects upon $\alpha_{1}-\mathrm{Pi}$ of oxidants generated from phagocytes during the "respiratory burst," independently of the release of azurophilic granule proteases (which are also capable of inactivating the inhibitor), we used PMA to stimulate $P M N$ respiration under conditions in which azurophil degranulation is minimal $(18,19)$. PMA was also used to stimulate the respiratory burst in MNC and PAM (18). Human PMN, MNC, or PAM were incubated with PMA in the presence of either human serum inhibitors or cytochrome $c$, unless otherwise noted. After $30 \mathrm{~min}$ at $37^{\circ} \mathrm{C}$ in a gyrorotary water bath, the cells were removed by centrifugation and the supernates were assayed for either EIC or reduced cytochrome $c$ as described in Methods. Superoxide generation was observed in the medium surrounding PMA stimulated phagocytes (Table I). The EIC of serum or purified $\alpha_{1}-\mathrm{Pi}$ incubated with PMA-stimulated phagocytes was partly suppressed (Table I). Neither PMA alone nor phagocytes without PMA significantly affected serum EIC (Table I). Control experiments ruled out activation of elastase by products of stimulated phagocytes (Table I).

TABLE I

Suppression of the EIC of Human Serum or $\alpha_{1}-P i$ by Stimulated Human Phagocytes

\begin{tabular}{|c|c|c|c|c|c|c|}
\hline \multicolumn{5}{|c|}{ Incubation mixture* } & \multicolumn{2}{|c|}{ Assay results $\llbracket$} \\
\hline Cell type & $\mathrm{CH}_{3} \mathrm{OH}$ & PMA & Serum & $\alpha_{1}-P_{i}$ & $\mathrm{O}_{2} \S$ & EIC" \\
\hline - & - & - & - & - & NTT & $0^{* *}$ \\
\hline - & + & + & - & - & NT & $0 * *$ \\
\hline - & - & - & + & - & NT & 100 \\
\hline - & + & + & + & - & NT & $98 \pm 9$ \\
\hline PMN & + & - & + & - & 0 & $97 \pm 9$ \\
\hline PMN & + & + & + & - & 100 & $45 \pm 6$ \\
\hline PMN & + & + & - & - & $93 \pm 5$ & $0^{* *}$ \\
\hline MNC & + & - & + & - & $8 \pm 3$ & $95 \pm 5$ \\
\hline MNC & + & + & + & - & 100 & $52 \pm 8$ \\
\hline MNC & + & + & - & - & $95 \pm 9$ & $0^{* *}$ \\
\hline PAM & + & - & + & - & $24 \pm 14$ & $90 \pm 11$ \\
\hline PAM & + & + & + & - & 100 & $55 \pm 5$ \\
\hline PAM & + & + & - & - & $92 \pm 9$ & $0^{* *}$ \\
\hline PMN(CGD) & + & + & + & - & 0 & $97 \pm 9$ \\
\hline PMN(CGD) & + & + & - & - & NT & $0^{* *}$ \\
\hline MNC(CGD) & + & + & + & - & 0 & $96 \pm 8$ \\
\hline MNC(CGD) & + & + & - & - & NT & $0^{* *}$ \\
\hline- & - & - & - & + & NT & 100 \\
\hline - & + & + & - & + & NT & $98 \pm 7$ \\
\hline PMN & + & - & - & + & 0 & $95 \pm 5$ \\
\hline PMN & + & + & - & + & 100 & $30 \pm 5$ \\
\hline
\end{tabular}

* Concentrations: cells $=1.6 \times 10 \% / \mathrm{ml}$ in all cases; PMA $=1.5 \mathrm{ng} / \mathrm{ml}$ with PMN or MNC and $100 \mathrm{ng} / \mathrm{ml}$ with PAM; $\mathrm{CH}_{3} \mathrm{OH}$ (PMA solvent) $=0.03 \%$ (vol/vol); human serum $=4 \%(\mathrm{vol} / \mathrm{vol})$; pure $\alpha_{1}-\mathrm{Pi}=0.15 \mu \mathrm{g} / \mu \mathrm{l}$. The buffer was HBSSG ( $\mathrm{pH} \mathrm{7.8)}$.

$\ddagger$ The results are expressed as the mean of three experiments \pm 1 SEM.

$\S$ The results given in the table are expressed as a percent of the amount of $\mathrm{O}_{2}^{-}$generated by PMA-stimulated leukocytes of each cell type. $100 \%$ corresponds to $37 \pm 7 \mathrm{nM} \mathrm{O}_{2}^{-} / 1.6$ $\times 10^{6} \mathrm{PMN}, 22 \pm 5 \mathrm{nM} \mathrm{O}_{2}^{-} / 1.6 \times 10^{6} \mathrm{MNC}$, and $18 \pm 4 \mathrm{nM} \mathrm{O}_{2}^{-} / 1.6 \times 10^{6} \mathrm{PAM}$.

" EIC $=$ elastase standard - elastase + serum $\left(\right.$ or $\left.\alpha_{1}-\mathrm{Pi}\right) /$ elastase standard $\times 100$. The results given in the table are expressed as a percent of the EIC of serum or purified $\alpha_{1}-\mathrm{Pi}$ incubated with buffer alone.

I NT, not tested.

** Controls for the effects of all reagents on the activity of elastase. EIC $=0$ represents $100 \%$ enzyme activity. 
The EIC of serum remained unchanged when fresh serum was incubated with supernates, obtained by prior exposure of PMN, MNC, or PAM to PMA in serum-free HBSSG, and then centrifuged. This suggests that stable products (such as proteases) released from PMA-stimulated phagocytes were not responsible for suppression of serum EIC in the experiments summarized in Table I. Other evidence against $\alpha_{1}$-Pi-inactivation by azurophil granule proteases includes $(a)$ failure to detect $\alpha_{1}-\mathrm{Pi}$-protease complexes by crossed immunoelectrophoretic analysis (data not shown), (b) failure of chronic granulomatous disease PMN or MNC (in which degranulation is normal but generation of oxidants is defective) to inactive $\alpha_{1}-\mathrm{Pi}$ (see below) and (c), $\beta$-glucuronidase and MPO detection in amounts $\leq 1 \%$ of their total cellular content in supernates from PMAstimulated PMN and MNC. Although some enzyme may have adhered to cell membranes during centrifugation, this last observation implies that significant bulk release of azurophil granule enzymes had not taken place after PMA stimulation. The foregoing results suggest that bulk release of azurophil granule proteases was not responsible for the observed suppression of serum EIC. Whereas proteases inactivate the inhibitor stoichiometrically (13), azurophil granule MPO is able to catalytically inactivate $\alpha_{1}-\mathrm{Pi}$. Evidence follows to suggest that small quantities of released MPO, acting catalytically, may play a role in the suppression of serum EIC by PMA-stimulated phagocytes.

IEP analysis of serum inactivated by PMA-stimulated phagocytes. To demonstrate that the decrease in serum EIC was due to inactivation of $\alpha_{1}-\mathrm{Pi}$, serum samples whose EIC had been previously suppressed by PMA-stimulated phagocytes were incubated with elastase and then analyzed by IEP as described in Methods. As shown in Fig. 1A, $\alpha_{1}-\mathrm{Pi}$ present in control serum was able to complex all of the added elastase (Fig. 1A). In contrast, $\alpha_{1}-\mathrm{Pi}$ in serum incubated with PMA-stimulated PMN did not complex all of the added elastase and free elastase could be detected migrating toward the cathode (Fig. 1B). Similar results were obtained with serum previously incubated with PMA-stimulated MNC or PAM (results not shown). As illustrated in Fig. 1, inactivation of $\alpha_{1}$-Pi did not change its immunoreactivity or native electrophoretic mobility. Destruction or endocytosis of $\alpha_{1}-\mathrm{Pi}$ by the leukocytes was not responsible for the decreased EIC, since rocket IEP showed no change in $\alpha_{1}$-Pi concentration after incubation with PMA-stimulated cells (not shown).

Reactivation of serum EIC after incubation with PMA-stimulated phagocytes by treatment with dithiothreitol. In view of the wide range of oxidant species generated by PMA-stimulated phagocytes (11) and the known sensitivity of $\alpha_{1}-\mathrm{Pi}$ to oxidative inactivation $(7-10)$, it seemed likely that oxidative mechanisms were responsible for inactivation of $\alpha_{1}-\mathrm{Pi}$. To test this,

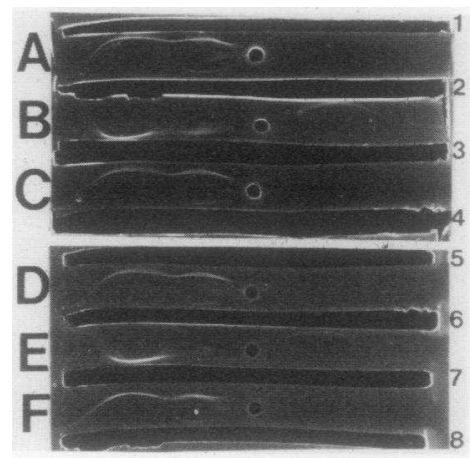

FIGURE 1 Immunoelectrophoretic analysis of mixtures of elastase and serum under various experimental conditions. Troughs $1,3,5$, and 7 contain rabbit antiserum to human $\alpha_{1}-\mathrm{Pi}$. Troughs $2,4,6$, and 8 contain rabbit antiserum to porcine pancreatic elastase. Anode to the left, cathode to the right. (A) Elastase added to control serum that had been incubated with unstimulated PMN. Note the presence of free $\alpha_{1}-\mathrm{Pi}$ migrating toward the anode, followed by complexes of $\alpha_{1}-\mathrm{Pi}$ and elastase. No free elastase was detected. (B) Elastase added to serum that had been incubated with PMA-stimulated PMN. Note increased free $\alpha_{1}-\mathrm{Pi}$, decreased $\alpha_{1}-\mathrm{Pi}$ : elastase complexes and uncomplexed elastase migrating toward the cathode. (C) Elastase added to serum that had been previously treated as in B, followed by treatment with DTT (see text). In contrast to $\mathrm{B}$, no free elastase was detected and increased $\alpha_{1}$-Pi-elastase complexes were present. (D) Elastase added to control serum that had been previously incubated with glucose oxidase $+\mathrm{Cl}^{-}$. Note the presence of $\alpha_{1}$-Pi-elastase complexes. No free elastase was detected. (E) Elastase added to serum that had been previously incubated with MPO + glucose oxidase $+\mathrm{Cl}^{-}$. Note decreased $\alpha_{1}$-Pi-elastase complexes and uncomplexed elastase migrating toward the cathode. (F) Elastase added to serum that had been previously treated as in E, followed by treatment with DTT (see text). In contrast to $\mathrm{E}$, no free elastase was detected and increased $\alpha_{1}$-Pi-elastase complexes were present. In A and B the conditions and concentrations are as described in Table I. In D and $E$ the conditions and concentrations are as described in Table IV.

samples of serum, inactivated by PMA-stimulated phagocytes (PMN, MNC, or PAM), were dialyzed against a reducing agent $(5 \mathrm{mM}$ dithiothreitol) (DTT) in $0.05 \mathrm{M}$ phosphate buffer ( $\mathrm{pH} 8.1$ ) for $24 \mathrm{~h}$ in the cold. This was followed by $3 \mathrm{~h}$ of dialysis against fresh reagent at $37^{\circ} \mathrm{C}$. As shown in Table II, treatment with DTT led to significant recovery of EIC in serum that had been incubated with PMA-stimulated phagocytes. DTT treatment had no effect on control serum or elastase alone (Table II). Reactivation of $\alpha_{1}$-Pi by DTT was confirmed by IEP analysis (Fig. 1C).

Protection of serum EIC from inactivation by PMAstimulated phagocytes. Human MNC and neutrophils contain MPO within their azurophilic lysosomal granules (20). MPO plus a source of $\mathrm{H}_{2} \mathrm{O}_{2}$ and an oxidizable halide cofactor can catalyze a wide range of oxidation and halogenation reactions which are thought to mediate the microbicidal activity of the MPO system (21). Although PMA stimulates phagocyte respiration (in- 
TABLE II

Reactivation of Serum EIC After Incubation with PMA-stimulated Phagocytes by Treatment with DTT

\begin{tabular}{|c|c|c|c|c|c|}
\hline \multicolumn{4}{|c|}{ Incubation mixture* } & \multirow{2}{*}{$\frac{\begin{array}{c}\text { Post-incubation } \\
\text { treatment }\end{array}}{\text { DTT } \$}$} & \multirow{2}{*}{$\frac{\text { Assay results }}{\text { EIC }}$} \\
\hline Cell type & $\mathrm{CH}_{3} \mathrm{OH}$ & PMA & Serum & & \\
\hline PMN & + & + & + & - & $44 \pm 8$ \\
\hline PMN & + & + & + & + & $88 \pm 7$ \\
\hline PMN & + & - & + & + & $94 \pm 5$ \\
\hline MNC & + & + & + & - & $50 \pm 7$ \\
\hline MNC & + & + & + & + & $84 \pm 7$ \\
\hline MNC & + & - & + & + & $96 \pm 6$ \\
\hline PAM & + & + & + & - & $56 \pm 6$ \\
\hline PAM & + & + & + & + & $89 \pm 8$ \\
\hline PAM & + & - & + & + & $101 \pm 8$ \\
\hline- & + & + & + & - & $97 \pm 9$ \\
\hline- & + & + & + & + & $96 \pm 8$ \\
\hline- & + & + & - & - & $0^{\|}$ \\
\hline- & + & + & - & + & $0^{\prime \prime}$ \\
\hline
\end{tabular}

* All concentrations and conditions are as described in Table I. $\$$ The results are expressed as the mean of three experiments \pm 1 SEM. EIC as defined in Table I.

$\S \mathrm{DTT}=5 \mathrm{mM}$ in $0.05 \mathrm{M}$ phosphate buffer ( $\mathrm{pH}$ 8.1).

"Controls for the effects of all reagents on the activity of elastase. $\mathrm{EIC}=0$ represents $100 \%$ enzyme activity.

cluding $\mathrm{H}_{2} \mathrm{O}_{2}$ production), it induces only minimal azurophil degranulation $(18,19)$. Since MPO is capable of catalytically inactivating $\alpha_{1}-\mathrm{Pi}$, small quantities of this enzyme (released following PMA stimulation), combined with $\mathrm{H}_{2} \mathrm{O}_{2}$ generated by the respiratory burst, and extracellular halide could have helped oxidize serum inhibitors in our experiments. This would be consistent with a previous report implicating extracellular MPO activity in the tumoricidal action of PMAstimulated PMN (22). We tested this possibility and were able to demonstrate that $0.3 \mathrm{mM} \mathrm{NaN}_{3}$ (an inhibitor of heme enzymes such as MPO) partially protected serum EIC from inactivation by PMA-stimulated PMN and MNC, without affecting $\mathrm{O}_{2}^{-}$production (Table III). Higher concentrations of azide (up to $4 \mathrm{mM}$ ) did not result in increased protection; although serum EIC was protected by concentrations of azide down to $0.06 \mathrm{mM}$ (data not shown). In addition, $0.5 \mathrm{mM} \mathrm{KCN}$ (also an inhibitor of heme enzymes), protected serum EIC from inactivation by PMA-stimulated PMN (Table III). CAT, which decreases available $\mathrm{H}_{2} \mathrm{O}_{2}$, essentially completely protected serum EIC (Table III). Heat-inactivated CAT (HICAT) did not protect serum EIC (Table III). CAT does not affect elastase alone (Table III). However, $75 \mathrm{mM} \mathrm{H}_{2} \mathrm{O}_{2}$ alone (an amount far in excess of that generated in the present system) does not suppress serum EIC (data not shown). Furthermore, incubation of serum (dialyzed against $0.15 \mathrm{M}$ phosphate buffer to deplete $\mathrm{Cl}^{-}$) with PMN stimulated by PMA in a medium lacking $\mathrm{Cl}^{-}$( $160 \mathrm{mM}$ sucrose, $10 \mathrm{mM}$ HEPES, $0.3 \mathrm{mM}$ calcium acetate and $50 \mathrm{mM}$ Na phosphate, $\mathrm{pH}$ 7.8) also partially protected serum EIC $(\mathrm{EIC}=70 \pm 5 \%$ of control, mean of three experiments \pm 1 SEM). Superoxide production was not significantly affected by such treatment. The addition of $\mathrm{Cl}^{-}$to the medium $(160 \mathrm{mM}$ sucrose, $10 \mathrm{mM}$ HEPES, $0.3 \mathrm{mM}$ calcium acetate and $50 \mathrm{mM} \mathrm{NaCl}, \mathrm{pH} 7.8)$ eliminated protection $(\mathrm{EIC}=49$ $\pm 8 \%$ of control, mean of three experiments \pm 1 SEM), suggesting that inactivation of $\alpha_{1}-\mathrm{Pi}$ is partly dependent on a halide cofactor.

In addition to the MPO system, phagocytic oxidizing capacity is believed to arise, in part, from the interaction of $\mathrm{O}_{2}^{-}$and $\mathrm{H}_{2} \mathrm{O}_{2}$ (produced during the respiratory burst) with trace metal catalysts present in biological fluids $(11,23,24)$. Such an interaction may give rise to more potent oxidants, thought to include species with reactivity similar to that of the hydroxyl radical $(11,23,24)$. For this reason, SOD was also tested for its ability to protect serum EIC from inactivation by PMA-stimulated PMN or MNC. As shown in Table III, SOD partially protected serum EIC. SOD does not affect elastase alone (Table III). Heat-inactivated SOD failed to protect serum EIC (Table III). SOD specifically catalyzes the dismutation of $\mathrm{O}_{2}^{-}$into $\mathrm{H}_{2} \mathrm{O}_{2}+\mathrm{O}_{2}$ (16) and was able to partially protect serum EIC. This implies that $\mathrm{O}_{2}^{-}$-dependent reactions may play a role in the inactivation of $\alpha_{1}-\mathrm{Pi}$. The observed protective effect of CAT (Table III) may be because less $\mathrm{H}_{2} \mathrm{O}_{2}$ is available for reaction with $\mathrm{O}_{2}^{-}$(in addition to less $\mathrm{H}_{2} \mathrm{O}_{2}$ available to the MPO system).

Several radical scavengers, capable of reacting with - $\mathrm{OH}$ but not with $\mathrm{H}_{2} \mathrm{O}_{2}$ or $\mathrm{O}_{2}^{-}(23,25)$, were next tested for their ability to protect serum EIC. Mannitol (Table III), benzoate $(20 \mathrm{mM})$, or ethanol $(30 \mathrm{mM})$ (data not shown) failed to protect serum EIC from PMA-stimulated PMN, MNC, or PAM. In the present system this suggests that oxidants as reactive as hydroxyl radical are probably not the proximate oxidants responsible for inactivation of $\alpha_{1}-\mathrm{Pi}$.

Our results therefore indicate that the suppression of serum EIC by PMA-stimulated phagocytes is effected in part by the MPO-system and by $\mathrm{O}_{2}^{-}$-dependent reactions as well. The partially protective effect of azide or cyanide (Table III) and $\mathrm{Cl}^{-}$depletion (see above) implicate the MPO system. In addition, the partially protective effect of SOD (Table III) suggests that $\mathrm{O}_{2}^{-}$-dependent reactions may also be involved. Furthermore, by combining SOD and azide, serum EIC is essentially completely protected (Table III). The complete protection provided by CAT (Table III) is also consistent with the proposed involvement of $\mathrm{H}_{2} \mathrm{O}_{2}$ in both MPO and $\mathrm{O}_{2}^{-}$-dependent pathways of $\alpha_{1}-\mathrm{Pi}$ inactivation.

Further study is necessary to determine whether 
TABLE III

Protection of Serum EIC from Inactivation by PMA-stimulated Phagocytes

\begin{tabular}{|c|c|c|c|c|c|}
\hline \multicolumn{4}{|c|}{ Incubation mixture* } & \multirow{2}{*}{\multicolumn{2}{|c|}{ Assay Results $\llbracket$}} \\
\hline & PMA & & & & \\
\hline Cell type & (in $\mathrm{CH}_{3} \mathrm{OH}$ ) & Serum & Protective agent & $\mathrm{O}_{2}^{-}$ & EIC \\
\hline PMN & + & + & - & 100 & $45 \pm 6$ \\
\hline PMN & + & + & SOD & 0 & $64 \pm 7$ \\
\hline PMN & + & + & CAT & $95 \pm 7$ & $89 \pm 5$ \\
\hline PMN & + & + & HISOD & $97 \pm 8$ & $42 \pm 6$ \\
\hline PMN & + & + & HICAT & $96 \pm 8$ & $47 \pm 5$ \\
\hline PMN & + & + & $\mathrm{NaN}_{3}$ & $95 \pm 9$ & $75 \pm 6$ \\
\hline PMN & + & + & $\mathrm{KCN}$ & $103 \pm 9$ & $73 \pm 8$ \\
\hline PMN & + & + & Mannitol & $102 \pm 8$ & $46 \pm 7$ \\
\hline MNC & + & + & - & 100 & $52 \pm 8$ \\
\hline MNC & + & + & SOD & 0 & $70 \pm 6$ \\
\hline MNC & + & + & CAT & $97 \pm 8$ & $95 \pm 7$ \\
\hline MNC & + & + & HISOD & $103 \pm 7$ & $50 \pm 7$ \\
\hline MNC & + & + & HICAT & $95 \pm 9$ & $54 \pm 8$ \\
\hline MNC & + & + & $\mathrm{NaN}_{3}$ & $101 \pm 8$ & $77 \pm 6$ \\
\hline MNC & + & + & Mannitol & $96 \pm 8$ & $50 \pm 9$ \\
\hline PMN & + & + & $\mathrm{SOD}+\mathrm{NaN}_{3}$ & 0 & $92 \pm 6$ \\
\hline- & + & - & SOD & - & $0 \S$ \\
\hline- & + & - & CAT & - & $0 \S$ \\
\hline- & + & - & $\mathrm{NaN}_{3}$ & - & $0 \$$ \\
\hline
\end{tabular}

* Concentrations: SOD and heat inactivated SOD (HISOD) $=400 \mathrm{U} / \mathrm{ml} ; \mathrm{CAT}$ and HICAT $=1,500 \mathrm{U} / \mathrm{ml} ; \mathrm{NaN}_{3}=0.3 \mathrm{mM} ;$ mannitol $=30 \mathrm{mM} ; \mathrm{KCN}=0.5 \mathrm{mM}$. All other concentrations and conditions are as described in Table $\mathrm{I}$.

$\ddagger$ The results are expressed as the mean of three experiments \pm 1 SEM. EIC as defined in Table 1.

$\S$ Controls for the effects of all reagents on the activity of elastase. EIC $=0$ represents $100 \%$ enzyme activity.

these reactions are responsible for the observed inactivation of $\alpha_{1}-\mathrm{Pi}$ by PAM. It is currently thought that mature human macrophages do not contain MPO (20). However, macrophages may contain other forms of peroxidase $(20,26)$, so that these cells may also be able to catalyze peroxidative reactions.

Suppression of EIC of $\alpha_{1}-P i$ by MPO + glucose oxidase $+\mathrm{Cl}^{-}$in a cell-free system. The data suggesting that the MPO system is partly responsible for oxidative inactivation of $\alpha_{1}-\mathrm{Pi}$ by PMA-stimulated PMN and MNC are consistent with our previous report (12). There we showed that an azide-inhibitable factor, possibly MPO, was also partly responsible for inactivation of $\alpha_{1}-\mathrm{Pi}$ by PMN stimulated with opsonized immune complexes. In addition, purified MPO, in a cell-free system, has been shown to inactivate purified $\alpha_{1}-\mathrm{Pi}$ at a $\mathrm{pH}$ of 6.1 (13). The $\mathrm{pH}$ in the vicinity of phagocytes is not known with precision. Even at sites of acute inflammation, however, extracellular $\mathrm{pH}$ is thought not to fall below 6.8 (27). Thus, if MPO can catalyze the inactivation of $\alpha_{1}-\mathrm{Pi}$ extracellularly, the effect should be demonstrable at physiological $\mathrm{pH}$.

We tested this possibility in vitro. Serum or purified
$\alpha_{1}-\mathrm{Pi}$ (both dialyzed against $0.05 \mathrm{M}$ phosphate buffer (pH 7.4) for $6 \mathrm{~h}$ in the cold to remove $\mathrm{Cl}^{-}$) were incubated with MPO plus a glucose oxidase $\mathrm{H}_{2} \mathrm{O}_{2}$-generating system and $\mathrm{Cl}^{-}$. After $15 \mathrm{~min}$ at $37^{\circ} \mathrm{C}$ in a gyrorotary water bath, the EIC was assayed as described in Methods. As shown in Table IV, MPO + glucose oxidase $+\mathrm{Cl}^{-}$suppressed the EIC of serum or purified $\alpha_{1}-\mathrm{Pi} . \mathrm{MPO}+$ glucose oxidase $+\mathrm{Cl}^{-}$had no effect on elastase activity alone (Table IV). We determined that the presence of enzymatically active MPO was essential for suppression of EIC since $\mathrm{NaN}_{3}$, an inhibitor of MPO activity, prevented the suppression and heatinactivated MPO was also ineffective (see Table IV). Hydrogen peroxide (supplied by glucose oxidase) was also required, because catalase prevented suppression of serum EIC (Table IV). However, $\mathrm{H}_{2} \mathrm{O}_{2}$ alone (supplied by glucose oxidase) failed to suppress serum EIC (Table IV). In addition, the presence of a halide cofactor $\left(\mathrm{Cl}^{-}\right)$was also essential for suppression (Table IV).

Decreased serum EIC after incubation with the MPO system was confirmed by IEP (Fig. ID, and E). In addition, treatment of MPO-inactivated serum with DTT (under conditions identical to those previously used to 
TABLE IV

Suppression of the EIC of Serum or Purified $\alpha_{1}-\mathrm{Pi}$ by MPO + Glucose Oxidase $+\mathrm{Cl}^{-}$

\begin{tabular}{|c|c|c|c|c|c|c|}
\hline \multicolumn{5}{|c|}{ Incubation mixture* } & \multirow{2}{*}{$\begin{array}{l}\text { Protective } \\
\text { agent }\end{array}$} & \multirow{2}{*}{$\frac{\text { Assay results } 1}{\text { EIC }}$} \\
\hline MPO & Glucose oxidase & $\mathrm{Cl}^{-}$ & Serum & $\alpha_{1}-\mathrm{Pi}$ & & \\
\hline- & - & - & + & - & - & 100 \\
\hline+ & + & + & + & - & - & $13 \pm 4$ \\
\hline- & + & + & + & - & - & $97 \pm 8$ \\
\hline+ & - & + & + & - & - & $97 \pm 9$ \\
\hline+ & + & - & + & - & - & $101 \pm 8$ \\
\hline HIMPO & + & + & + & - & - & $102 \pm 8$ \\
\hline+ & + & + & + & - & $\mathrm{NaN}_{3}$ & $95 \pm 7$ \\
\hline+ & + & + & + & - & CAT & $93 \pm 10$ \\
\hline+ & + & + & + & - & HICAT & $12 \pm 6$ \\
\hline+ & + & + & + & - & Mannitol & $14 \pm 8$ \\
\hline+ & + & + & + & - & SOD & $16 \pm 9$ \\
\hline- & - & - & - & - & - & $0 \$$ \\
\hline+ & + & + & - & - & - & $0 \$$ \\
\hline+ & + & + & - & - & $\mathrm{NaN}_{3}$ & $0 \$$ \\
\hline+ & + & + & - & - & CAT & $0 \$$ \\
\hline- & - & - & + & - & $\mathrm{NaN}_{3}$ & $95 \pm 6$ \\
\hline- & - & - & + & - & CAT & $97 \pm 5$ \\
\hline- & + & + & - & + & - & $95 \pm 8$ \\
\hline+ & + & + & - & + & - & $4 \pm 5$ \\
\hline
\end{tabular}

* Concentrations: MPO and heat-inactivated MPO (HIMPO) $=30 \mathrm{mU} / \mathrm{ml}$; glucose oxidase $=50 \mathrm{mU} / \mathrm{ml} ; \mathrm{NaCl}=0.15 \mathrm{M}$; human serum $=7.5 \% \mathrm{vol} / \mathrm{vol}$ (dialyzed against $0.05 \mathrm{M}$ phosphate buffer, $\mathrm{pH} 7.4$, before use); purified $\alpha_{1}-\mathrm{Pi}=0.15 \mu \mathrm{g} / \mu \mathrm{l}$ (dialyzed against $0.05 \mathrm{M}$ phosphate buffer, pH 7.4, before use); CAT or HICAT $=2,500 \mathrm{U} / \mathrm{ml} ; \mathrm{NaN}_{3}=2 \mathrm{mM}$; SOD $=400$ $\mathrm{U} / \mathrm{ml}$; mannitol $=30 \mathrm{mM}$. The final concentration of buffer was $0.05 \mathrm{M}$ phosphate, containing $30 \mathrm{mM}$ glucose ( $\mathrm{pH}$ 7.4).

$\downarrow$ Results are expressed as the mean of three experiments \pm 1 SEM. EIC as defined in Table I. $\S$ Controls for the effects of all reagents on the activity of elastase. EIC $=0$ represents $100 \%$ enzyme activity.

reactivate phagocyte-inactivated $\alpha_{1}-\mathrm{Pi}$ ) resulted in $80 \pm 7 \%$ (mean of three experiments \pm 1 SEM) recovery of EIC. Reactivation of $\alpha_{1}$-Pi was also confirmed by IEP (Fig. 1F).

Experiments with metabolically-defective phagocytes. Our results suggest that $\mathrm{O}_{2}^{-}, \mathrm{H}_{2} \mathrm{O}_{2}$, and MPO generate oxidants capable of inactivating $\alpha_{1}-\mathrm{Pi}$. We supported this conclusion further with an experiment using MNC and PMN from a patient with chronic granulomatous disease (CGD). Leukocytes from patients with this disorder do not undergo an effective respiratory burst during phagocytosis and do not generate significant concentrations of $\mathrm{O}_{2}^{-}$or $\mathrm{H}_{2} \mathrm{O}_{2}$ (11). After incubation with PMA, neither CGD-PMN nor CGD-MNC produced detectable levels of $\mathrm{O}_{2}^{-}$and they also failed to suppress serum EIC (Table I). The findings with CGD leukocytes strongly imply that inactivation of $\alpha_{1}-\mathrm{Pi}$ depends on phagocyte products generated by the respiratory burst.

\section{DISCUSSION}

Previous work has implicated phagocyte-derived oxidants, whose generation is dependent on $\mathrm{H}_{2} \mathrm{O}_{2}$ and
$\mathrm{O}_{2}^{-}$, as tissue damaging agents in inflammation because of oxidant cytotoxicity (28), oxidant-mediated degradation of structural polysaccharides (29), oxidantmediated microbicidal effects, and the reported antiinflammatory effects of SOD (30). MPO has been shown to be responsible for tumor cell cytotoxicity (22) and platelet stimulation (31) mediated by activated PMN. In a cell-free system, MPO has also been shown to inactivate the chemotactic factors $\mathrm{C}_{5 \mathrm{a}}$ and f-Met-Leu-Phe (21). In addition, oxidants released from inflammatory cells at sites of acute or chronic inflammation could alter the local balance between proteases and antiproteases. This would result from the oxidative inactivation of $\alpha_{1}-\mathrm{Pi}$, rendering adjacent tissue structures more susceptible to damage by proteases simultaneously released from inflammatory phagocytes. This is supported by our data as well as by previous studies $(12,13)$.

Hydrogen peroxide and $\mathrm{O}_{2}^{-}$produced during the respiratory burst may be released extracellularly and interact to generate oxidants capable of inactivating $\alpha_{1}-\mathrm{Pi}$. In this context, it is important to note that normal extracellular fluids contain only traces of SOD and CAT 
(29). In addition, MPO released from the lysosomal granules of PMN and $\mathrm{MNC}, \mathrm{H}_{2} \mathrm{O}_{2}$ secreted by these cells, and extracellular halide may also catalyze the oxidative inactivation of $\alpha_{1}-\mathrm{Pi}$. Thus, a spectrum of oxidative mechanisms exists through which phagocytes may inactivate $\alpha_{1}-\mathrm{Pi}$ in their local microenvironment.

Human $\alpha_{1}-\mathrm{Pi}$ contains a methionine residue in its elastase-combining site $(7,9)$. Oxidation to the sulfoxide form of methionine thioether residues in or near the active site of $\alpha_{1}-\mathrm{Pi}$ is associated with the loss of functional activity of the inhibitor (7-10) and may be the mechanism of $\alpha_{1}-\mathrm{Pi}$ inactivation by phagocyte oxidants. In fact, MPO has been shown to oxidize two methionine residues in purified $\alpha_{1}-\mathrm{Pi}$, at slightly acid $\mathrm{pH}$ (13). Methionine oxidation has also been proposed as the mechanism for the MPO-catalyzed inactivation of the chemotactic factors $\mathrm{C}_{5 \mathrm{a}}$ and f-Met-Leu-Phe (21). Oxidation of thio-ether residues to the sulfoxide form is a reversible reaction (32), which is consistent with our finding that reduction can reactivate phagocyte-inactivated $\alpha_{1}-\mathrm{Pi}$.

In our whole-cell system, the proximate oxidant(s) responsible for inactivation of $\alpha_{1}-\mathrm{Pi}$ appear(s) to be less reactive than $\cdot \mathrm{OH}$ since $\mathrm{EIC}$ was not protected by -OH scavengers (see Table III). Although a role for -OH must still be considered, data derived from using . OH scavengers in intact cell systems must be interpreted with caution. This is because the degree of inhibition reflects not only rate constants of interaction between scavengers and radicals, but also the ability of the scavengers to gain access to sites of radical generation. Furthermore, serum components may react with $\cdot \mathrm{OH}$ to generate secondary radicals unreactive toward $\cdot \mathrm{OH}$ scavengers, but sufficiently reactive to inactivate $\alpha_{1}-\mathrm{Pi}$. Under different conditions (12), where PMN stimulated by opsonized antigen-antibody complexes were used to suppress the serum EIC, agents similar to the hydroxyl radical did appear to be involved. Oxygen metabolites generated by PMN may differ in nature and quantity, depending on the agent and conditions used to stimulate phagocyte respiration (33). This may help explain why our present data concerning the role of $\cdot \mathrm{OH}$ contrast with our earlier results (12). Further studies are necessary to identify the proximate oxidant(s) involved in $\alpha_{1}$-Pi inactivation by stimulated phagocytes and to clarify the reactions and conditions leading to their generation.

DTT reversed the inactivation of $\alpha_{1}-\mathrm{Pi}$ by a cell-free MPO system or by PMA-stimulated phagocytes. We do not know if reducing systems are present in vivo that are capable of reactivating oxidized $\alpha_{1}-\mathrm{Pi}$. Such systems could, however, play a role in modulating tissue damage at sites of inflammation and should be studied further.

Finally, it has been demonstrated recently that immunologically stimulated murine macrophages can produce more $\mathrm{O}_{2}^{-}$when treated with PMA (34). Other evidence suggests that alveolar macrophages lavaged from the lungs of cigarette smokers can also produce more $\mathrm{O}_{2}^{-}$(35). The increased oxidative capacity of smokers' macrophages may enhance the oxidative inactivation of $\alpha_{1}$-Pi by macrophages in these individuals' lungs. Oxidative inactivation of $\alpha_{1}-\mathrm{Pi}$ in smokers' lungs could render alveolar connective tissue more susceptible to the destructive action of leukocyte proteases. Such mechanisms may play a role in the pathogenesis of pulmonary emphysema in cigarette smokers. This may help explain the recent observation that uncomplexed $\alpha_{1}-\mathrm{Pi}$ in the lungs of smokers is partly inactivated (36). It is also possible, however, that oxidants in cigarette smoke itself are responsible for this effect $(8,37)$.

Many questions remain, and further studies are necessary to firmly establish whether oxidative inactivation of $\alpha_{1}-\mathrm{Pi}$ by phagocyte-derived oxidants plays a role in mediating tissue injury at sites of inflammation in vivo. However, we believe that our observations strongly indicate this possibility and render it worthy of further study.

\section{ACKNOWLEDGMENTS}

We thank Drs. J. Gallin and A. Fauci (National Institute of Allergy and Infectious Diseases) for providing blood samples from a patient with chronic granulomatous disease, Drs. E. H. Bergofsky and A. Hurewitz (State University of New York at Stony Brook) for their assistance in obtaining human bronchopulmonary lavage specimens, and Drs. F. Miller and H. Godfrey (State University of New York at Stony Brook) for helping us to obtain blood samples from normal individuals. We are also grateful to Dr. W. Troll (New York University School of Medicine) for a gift of phorbol myristate acetate and to Dr. J. Schultz (Papanicolaou Cancer Research Institute) for providing purified myeloperoxidase.

Supported by U. S. Public Health Service grant HL 14262 and grant 1143 from the Council for Tobacco Research-U.S. A., Inc.

\section{REFERENCES}

1. Janoff, A. 1972. Neutrophil proteases in inflammation. Annu. Rev. Med. 23: 177-189.

2. Janoff, A., and J. Scherer. 1968. Mediators of inflammation in leukocyte lysosomes. IX. Elastinolytic activity in granules of human polymorphonuclear leukocytes.J. Exp. Med. 128: 1137-1155.

3. Schmidt, W. H., and K. Havemann. 1974. Isolation of elastase-like and chymotrypsin-like neutral proteases from human granulocytes. Hoppe-Seyler's Z. Physiol. Chem. 355: $1077-1082$.

4. Henson, P. M. 1971. The immunologic release of constituents from neutrophil leukocytes. I. The role of antibody and complement on nonphagocytosable surfaces or phagocytosable particles. J. Immunol. 107: 1535-1546.

5. White, R., H-S. Lin, and C. Kuhn III. 1977. Elastase secretion by peritoneal exudative and alveolar macrophages. J. Exp. Med. 146: 802-808.

6. Ohlsson, K. 1978. Interaction of granulocyte neutral proteases with alpha $a_{1}$-antitrypsin, alpha ${ }_{2}$-macroglobulin and 
alpha $_{1}$-antichymotrypsin. In Neutral Proteases of Human Polymorphonuclear Leukocytes. K. Havemann and A. Janoff, editors. Urban and Schwarzenberg, Inc., Baltimore. 167-177.

7. Johnson, D., and J. Travis. 1978. Structural evidence for methionine at the reactive site of human $\alpha$-1-proteinase inhibitor. J. Biol. Chem. 253: 7142-7144.

8. Carp, H., and A. Janoff. 1978. Possible mechanisms of emphysema in smokers. In vitro suppression of serum elastase-inhibitory capacity by fresh cigarette smoke and its prevention by antioxidants. Am. Rev. Respir. Dis. 118: 617-621.

9. Johnson, D., and J. Travis. 1979. The oxidative inactivation of human alpha-1-proteinase inhibitor: further evidence for methionine at the reactive center. J. Biol. Chem. 254: 4022-4026.

10. Cohen, A. B. 1979. The effects of in vivo and in vitro of oxidative damage to purified $\alpha_{1}$-antitrypsin and to the enzyme-inhibiting activity of plasma. Am. Rev. Respir. Dis. 119: 953-960.

11. Babior, B. M. 1978. Oxygen-dependent microbial killing by phagocytes. N. Engl. J. Med. 298: 659-668, 721-725.

12. Carp, H., and A. Janoff. 1979. In vitro suppression of serum elastase-inhibitory capacity by reactive oxygen species generated by phagocytosing polymorphonuclear leukocytes. J. Clin. Invest. 63: 793-797.

13. Matheson, N. R., P. S. Wong, and J. Travis. 1979. Enzymatic inactivation of human alpha-1-proteinase inhibitor by neutrophil myeloperoxidase. Biochem. Biophys. Res. Commun. 88: 402-409.

14. Boyum, A. 1974. Separation of blood leukocytes, granulocytes and lymphocytes. Tissue Antigens. 4: 269-274.

15. Bieth, J., B. Spiess, and C. G. Wermuth. 1974. The synthesis and analytical use of a highly sensitive and convenient substrate of elastase. Biochem. Med. 11:350-357.

16. McCord, J. M., and I. Fridovich. 1969. Superoxide dismutase. An enzymic function for erythrocuprein (hemocuprein). J. Biol. Chem. 244: 6049-6055.

17. Bretz, U., and M. Baggiolini. 1974. Biochemical and morphological characterization of azurophil and specific granules of human neutrophilic polymorphonuclear leukocytes. J. Cell Biol. 63: 251-269.

18. Hoidal, J. R., J. E. Repine, G. D. Beall, F. L. Rasp, and J. G. White. 1978. The effect of phorbol myristate acetate on the metabolism and ultrastructure of human alveolar macrophages. Am. J. Pathol. 91: 469-476.

19. Repine, J. E., J. G. White, C. C. Clawson, and B. M. Holmes. 1974. The influence of phorbol myristate on oxygen consumption by polymorphonuclear leukocytes. J. Lab. Clin. Med. 83: 911-920.

20. Klebanoff, S. J., and C. B. Hamon. 1975. Antimicrobial systems of mononuclear phagocytes. In Mononuclear Phagocytes in Immunity, Infection, and Pathology. R. Van Furth, editor. Blackwell Scientific Publications, Oxford. 507-529.

21. Clark, R. A., and S. J. Klebanoff. 1979. Chemotactic factor inactivation by the myeloperoxidase-hydrogen peroxidehalide system. An inflammatory control mechanism. J. Clin. Invest. 64: 913-920.

22. Clark, R. A. 1979. Toxic effects of myeloperoxidase and
$\mathrm{H}_{2} \mathrm{O}_{2}$ secreted by neutrophils exposed to a soluble stimulus. Clin. Res. 27: 209A.

23. Weiss, S. J., P. K. Rustage, and A. F. LoBuglio. 1978. Human granulocyte generation of hydroxyl radical. J. Exp. Med. 147: 316-323.

24. McCord, J. M., and E. D. Day. 1978. Superoxide dependent production of hydroxyl radical catalyzed by iron-EDTA complexes. FEBS (Fed. Eur. Biochem. Soc.) Lett. 86: 139-142.

25. Fong, K. L., P. B. McCay, J. L. Poyer, B. B. Keele, and H. Misra. 1973. Evidence that peroxidation of lysosomal membranes is initiated by hydroxyl free radicals produced during flavin enzyme activity. J. Biol. Chem. 248: $7792-7797$

26. Romeo, D., R. Cramer, T. Narzi, M. R. Soranzo, G. Zabucchi, and F. Rossi. 1973. Peroxidase activity of alveolar and peritoneal macrophages.J. Reticuloendothel. Soc. 13: 399-409.

27. Menkin, V. 1934. Studies on inflammation. X. The cytological picture of an inflammatory exudate in relation to its hydrogen ion concentration. Am. J. Pathol. 10: 193210.

28. Salin, M. L., and J. M. McCord. 1975. Free radicals and inflammation. Protection of phagocytosing leukocytes by superoxide dismutase. J. Clin. Invest. 56: 1319-1322.

29. McCord, J. M. 1974. Free radicals and inflammation: protection of synovial fluid by superoxide dismutase Science (Wash. D. C.). 185: 529-531.

30. Menander-Huber, K. B., and W. Huber. 1977. Orgotein, the drug version of bovine $\mathrm{Cu}-\mathrm{Zn}$ superoxide dismutase. II. A summary account of clinical trials in man and animals. In Superoxide and Superoxide Dismutases. A. M. Michelson, J. M. McCord, and I. Fridovich, editors. Academic Press, Inc., New York. 537-549.

31. Clark, R. A., and S. J. Klebanoff. 1977. Neutrophil-mediated release of serotonin from human platelets: role of myeloperoxidase and $\mathrm{H}_{2} \mathrm{O}_{2}$. Clin. Res. 25: 474A (Abstr.).

32. Jori, G., G. Galiazzo, A. Marzotto, and E. Scoffone. 1968. Selective and reversible photo-oxidation of the methionyl residues in lysozyme. J. Biol. Chem. 243: 4272-4278.

33. Segal, A. W., and O. T. G. Jones. 1979. Reduction and subsequent oxidation of a cytochrome $b$ of human neutrophils after stimulation with phorbol myristate acetate. Biochem. Biophys. Res. Commun. 88: 130-134.

34. Johnston, R. B., C. A. Godzik, and Z. A. Cohn. 1978. Increased superoxide anion production by immunologically activated and chemically elicited macrophages. J. Exp. Med. 148: 115-127.

35. Hoidal, J. R., R. B. Fox, H. E. Takiff, and J. E. Repine. 1979. Alveolar macrophages (AM) from young, asymptomatic cigarette smokers (CS) and non-smokers (NS) use equal amounts of oxygen $\left(\mathrm{O}_{2}\right)$ and glucose $\left(1^{-14} \mathrm{C}\right)$, but smokers (AM) make more superoxide anion $\left(\mathrm{O}_{2}^{-}\right)$. Am. Rev. Respir. Dis. 119: 222 (Abstr.).

36. Gadek, J. E., G. A. Fells, and R. G. Crystal. 1979. Cigarette smoking induces functional antiprotease deficiency within the lower respiratory tract of humans. Science (Wash. D. C.). 206: 1315-1316.

37. Janoff, A., H. Carp, D. K. Lee, and R. T. Drew. 1979. Cigarette smoke inhalation decreases alpha-1-antitrypsin activity in rat lung. Science (Wash. D. C.). 206: 1313-1314. 